\title{
Torakolomber omurga kırıklarında görüntüleme teknikleri
}

\author{
Imaging techniques in thoracolumbar spine fractures
}

\author{
Ümit Özgür Güler, Metin Özalay
}

Başkent Üniversitesi Adana Hastanesi

\begin{abstract}
Travmatik torakolomber omurga kırıkları sıklıkla görülen yaralanmalardandır. Bu kırıklar ile birlikte ligamentöz kompleks yaralanmaları görülebilmekte, bu yaralanmalar instabiliteye, geçici veya kalıcı nöral basıya neden olabilmektedir. Sonuçta, omurga travması yaşamı değiştirecek, uzun dönem etkileri olan ciddi zayıflıklara neden olabilecek bir travmadır. Uzun dönem istenmeyen etkileri engelleyebilmek için, spinal instabilitenin ve nörolojik durumun belirlenmesi omurga cerrahları için önemli konulardır. Bu nedenle, omurganın radyolojik görüntülenmesi ilk değerlendirmede önemli bir rol oynamaktadır.
\end{abstract}

Anahtar sözcülkler: omurga; travma; radyolojik değerlendirme
Traumatic fractures of the thoracolumbar spine are common. They may be associated with disruption of the ligamentous complexes, and can result in instability or compression of neural structures temporarily or permanently. So, spine trauma can be a devastating, life-altering injury that can have major debilitating, long-term effects. In order to prevent unwanted long term effects, determination of spinal instability and neurological status are important issues for spine surgeons. For this reason, imaging of the spine plays an important role in the initial evaluation.

Key words: spine; trauma; radiological examination

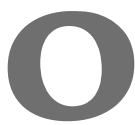

murga travmalarının değerlendirilmesi ve incelenmesi, iyi organize olmuş saha içi yönetim protokolleri ile kişiye özel tedavi planlaması ve tedavi içerisinde ortaya çıkabilecek ciddi ve hayatı tehdit edebilecek sorunlar ile, karmaşık, çok faktörlü bir süreçtir. Omurga ve omurilik travması; travma anında yıkıcı veya uzun süreli sekeller ile hastanın hayatında ciddi değişikliklere neden olabilen ve sonucunda yaşamı tehdit eden bir yaralanma olabilmektedir. Bu nedenle, kalıcı sorunların en aza indirilmesi ve uygun önlemlerin zamanında alınabilmesi için, kapsamlı ve doğru bir değerlendirmenin yapılması kritik öneme sahiptir. Bu görev, akut travma ortamında, ilişkili kafa travması veya madde kullanımı sonucu gelişmiş, değişmiş mental durum ve kooperasyon eksikliği gibi faktörlere ikincil olarak zor olabilir. Bu nedenle, omurga görüntülenmesi, omurga yaralanması olan hastanın ilk değerlendirilmesinde çok önemli bir rol oynar.

Direkt grafi (X-ray), omurga travması mevcut olan hastaların ilk değerlendirilmesinde uzun zamandan beridir standart olarak kullanılmaktadır. Travmaya maruz kalmış hastada hangi filmlerin gerekli olduğu yıllar içerisinde değişse de, genel olarak asıl tartışma servikal omurga değerlendirilmesi için yapılmaktadır. Bir kısım yazar yalnızca lateral grafinin yeterli olduğunu belirtirken, diğerleri ön-arka, odontoid ve oblik grafi ile de değerlendirme yapmak gerektiğini belirtmektedirler. Genel olarak kabul edilmiş standart bir görüntüleme taraması olmamakla birlikte, travmanın mekanizması, fizik muayene ve olası diğer yaralanmaların varlığı, görüntüleme yöntemlerinin asıl kılavuzudur.

Direkt grafiler, ilk bakı ve kemik patolojiyi değerlendirmesinde kullanışı olmasına rağmen, özellikle bağ, spinal kord ve diğer yumuşak doku yaralanmalarının değerlendirilmesinde sınırlı kalır. Direkt grafi değerlendirmeye göre daha ayrıntılı değerlendirme, bilgisayarlı tomografinin (BT) ve manyetik rezonans (MR) görüntülemenin kullanımı ile olmuştur. Özellikle, hemen her sağlık kuruluşunda olması ve daha rahat ulaşılabilmesi ile, BT multi-travma hastaların görüntülenmesinde önemli bir yere sahiptir. MR'nin yaygınlığının artması ve organ sistemlerini değerlendirmedeki başarısı,

- Illetişim adresi: Prof. Dr. Metin Özalay, Başkent Üniversitesi Adana Hastanesi, Yüreğir, Adana

Tel: 0322 - 3272727 / 12077 e-posta: metinozalay@gmail.com

- Geliș tarihi: 1 Kasım 2018 Kabul tarihi: 1 Kasım 2018 
onun da vazgeçilmez bir tetkik olmasını sağlamaktadır. BT ve beraberinde miyelografi; disk herniyasyonu ve hematom hakkında daha fazla bilgi verebilecekken, omurga travmasında miyelografinin kullanımının sınırlı olması nedeniyle, özellikle spinal kord patolojisi, hematom ve ödem değerlendirmesinde MR daha ön plana çıkmaktadır.

\section{DIREKT GRAFi iLE DEĞERLENDIRME}

Yüksek enerjili travmaya maruz kalmış hastalarda kabul görmüş radyolojik değerlendirme, üç yönlü servikal omurga grafisi şeklindedir. Servikal grafiye ek lomber ve torakal bölge grafileri, fizik muayene ve nörolojik muayeneye göre kişiye özel olarak yapılmalıdır. Yaralanma seviyesi tespit edilemediğinde ise servikal, torakal ve lomber bölgeyi içine alan tüm omurga grafileri çekilmelidir. Birçok çalışmada, tüm omurga grafisinin önemi anlatılmış ve özellikle $\% 5$ hastada tespit edilemeyen yaralanmalar neticesinde gecikmiş nörolojik kötüleşmenin görüldügüü bildirilmiştir. ${ }^{[1]}$ Genellikle, tespit edilemeyen yaralanmalar iki seviyeli kırıklarda, kafa travmalı hastalarda, üst servikal omurga yaralanmalarında ve servikotorasik yaralanmalarda görülmektedir. ${ }^{[2-4]}$ Bir diğer çalışmada, torasik ve lomber burst kırıkları olan 69 hastanın 30'unda diğer seviyelerde de omurga kırıkları tespit edilmiştir. ${ }^{[5]}$ Yine diğer bir çalışmada, omurga yaralanması olan 327 hastanın \%11'inde ardışık olmayan başka anatomik bölge yaralanmaları tespit edilmiştir. ${ }^{[2]}$ Ardışık olmayan yaralanmalar, ilerleyen dönemlerde instabilite ve nörolojik kötüleşmelere neden olabilir.

Torakolomber bölge grafileri ön-arka (AP) ve lateral olarak alınmalıdır. AP ve lateral göğüs ve abdomen grafileri omurga kemik değerlendirilmesi için yeterli olmayacaktır. Travmatik kırıkların yaklaşık $\% 60$ oranı ile en çok görüldüğü anatomik bölgeler olan alt torakal ve üst lomber seviyelerin en optimal şekilde görüntülendiği L2 seviyesi yan grafinin merkezi veya odak noktası olarak alınması hızlı bir değerlendirmeyi sağlayacaktır. Bu bölgenin daha çok travmaya maruz kalmasının birçok nedeni vardır; daha sert bir kosta ve kas yapısından göreceli olarak daha mobil ve desteksiz lomber bölgeye geçiş bölgesidir; ayrıca sagittal oryantasyonda kifotik torasik omurgadan lordotik lomber omurgaya geçiş bölgesi ve apofizyel eklemlerin de yönleniminde değişim bölgesidir. L2 odaklanmasına ek olarak yan grafide mutlaka diğer bir bileşke bölgesi olan lumbosakral bölge de iyi şekilde görüntülenmelidir. Torakal omurga üst seviye bölgelerinin omuz ve skapulalar nedeniyle tam olarak değerlendirilememesi nedeniyle, bazı çalışmalarda kollardan traksiyon uygulanan yüzücü grafisi veya oblik grafi önerilmektedir. $^{[6,7]}$ Bununla birlikte, yine torakal bölge posterior kolon elemanlarının değerlendirilmesi kosta ve yumuşak doku görüntüleri nedeniyle zor olabilmektedir. AP grafi ile posterior yaralanma bulguları olan interpediküler mesafenin artması, kemik yapıların devamlılığında bozulmalar veya pedikül, nöral ark yapılarında bozulmalar dikkatli şekilde değerlendirilmelidir. Yine, AP grafiye ek olarak lateral grafide dizilim bozukluğu, yükseklik kaybı, kifotik açılanma, interspinöz mesafenin artması mutlaka değerlendirilmelidir. Omur cismi çökmesi, kırık mesafenin ardışık omur yükseklikleri ile kıyaslanarak mutlaka yüzde olarak belirlenmeli ve not edilmelidir.

Chance kırıkları özel tip hiperfleksiyon yaralanmaları olup, genelde emniyet kemeri takmış kişilerde hızlı yavaşlama neticesinde üst lomber bölgede görülen orta ve posterior kolonu ilgilendiren kırık şeklidir. X-ray değerlendirilmesinde üç kolonun da yaralandığı sadece kemik veya kemik-bağ anatomik bölgelerini içeren kırık şeklinde tespit edilebilir. Bu kırık, genellikle yandaş yaralanmalar ile birlikte oluşmaktadır. Örneğin; spinal kord yaralanması, kauda ekina; dalak, pankreas veya duodenum, sigmoid kolon perforasyonu gibi. Bu tür bir yaralanma tespit edildiğinde mutlaka diğer organ patolojileri için ileri tetkikler yapılmalıdır. Fleksiyondistraksiyon yaralanmalarında posterior kolon ve yapılar distrakte olurken anterior kolon kompresyona uğramakta ve bu lateral grafide anterior cismin yükseklik kaybı ile birlikte posteriorda spinöz çıkıntılar arası mesafenin artmış şekilde olması olarak görülebilmektedir (Şekil 1).

Özellikle posterior kolonun sağlam olduğu anterior ve orta kolonun yaralandığı stabil burst kırıklarında gelişmiş akut kifoz derecesi yan grafide ölçülmelidir. Bu şekilde travma serisinde stabil olarak değerlendirilen ve konservatif tedavi ile takip edilecek hastalarda erken dönemde mutlaka korse ile ayakta grafiler çekilerek devam eden çökme veya ilerleyici kifoz olup olmadığı belirlenmelidir. Bir çalışmada T11 ve L2 kırığı olup konservatif tedavi uygulanan hastalarda ilerleyen takiplerinde cerrahi tedavi ilk travmada tespit edilememiş deformite için yapılması gerekmiştir. ${ }^{[8]}$

Travma serisinde yan grafi ölçümünde $15^{\circ}$ ve üzeri kifoz varlığı travmanın stabil olmayan bir kırığa neden olduğunu düşündürmekte, $30^{\circ}$ ve üzeri kifoz varlığı ise posterior bağ yaralanması olduğunu göstermektedir. ${ }^{[9]}$ Yine herhangi bir plandaki $2,5 \mathrm{~mm}$ ve fazla translasyon ile cisim yüksekliğinde $\% 50$ ve üzeri yükseklik kaybı, yine posterior bağ yaralanması ile birlikte makaslama yaralanmasını göstermektedir ${ }^{10]}$ ki bu, yaralanmanın stabil olmayan ve beraberinde yüksek oranda parapleji veya nörolojik defisit görülebilecek travma şekli olduğunu anlatmaktadır. Ancak, birçok travmada instabil kırık varlığında kanal kemik basısı ve özellikle posterior 

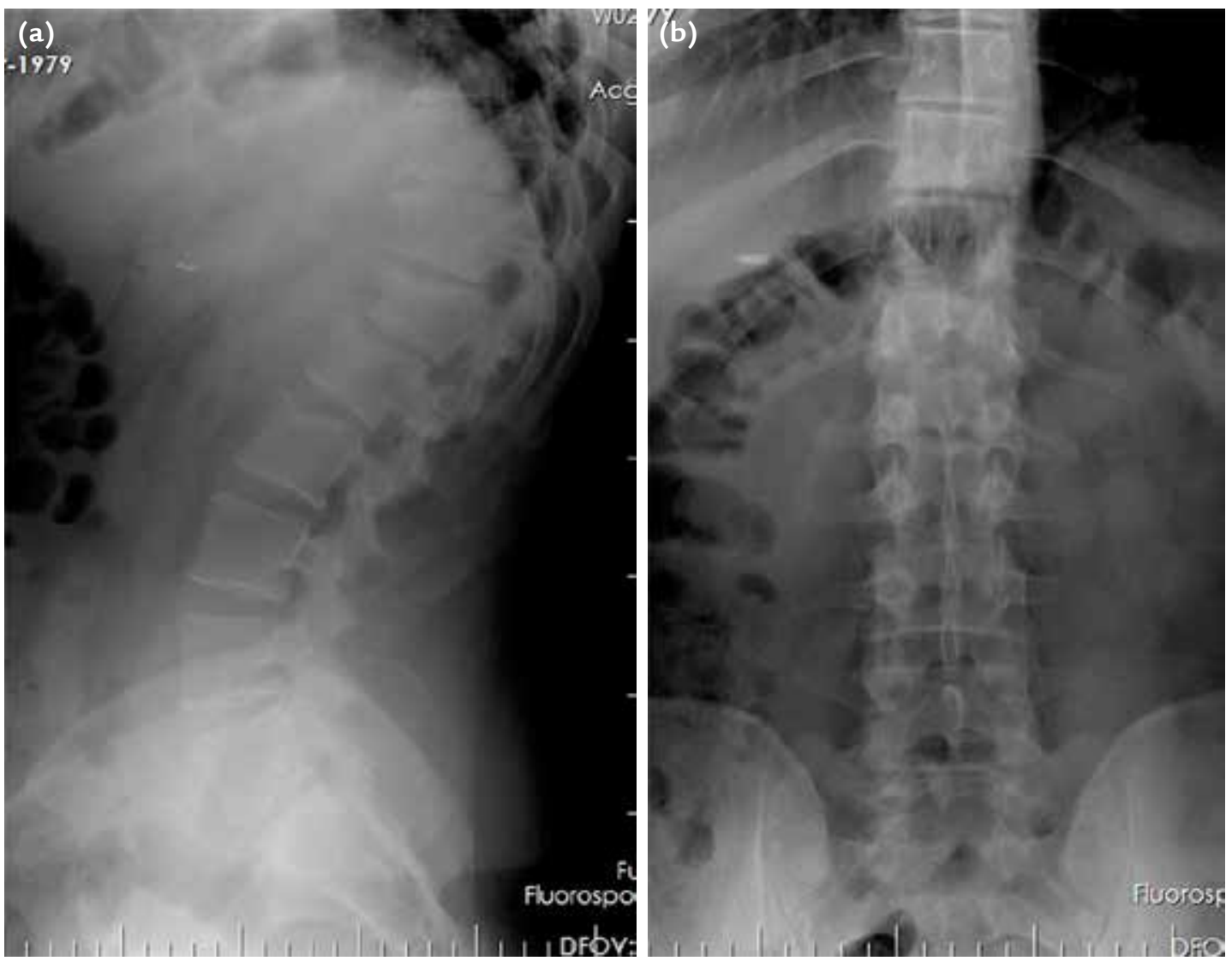

Şekil 1. a, b. Yüksekten düşme sonrası AP (a) ve lateral (b) lomber grafisi. T12, L1 ve L2 korpus ön yüzlerinde düzensizlik ve yükseklik kaybı görülmektedir. İnterspinöz aralıklar ve posterior kemik yapılar sağlam olarak değerlendirilmektedir.

kolon ve bağlarının değerlendirmesinde grafiler çoğunlukla yetersiz kalabilir ve diğer ileri tetkiklerin yapılmasını gerektirir.

\section{BILGISAYARLI TOMOGRAFI}

Yapılan çalışmalarda, yeterli kalite ve sayıda grafi tetkiki yapılmış hastaların \%5-8'inde, normal grafi bulgularına rağmen omurga kırığı olduğu tespit edilmiştir. ${ }^{[11-13]}$ Yine, torakolomber yaralanması olan hastaların takiplerinde yapılan BT tetkikinde \%25'inin patolojisinin burst kırığı olduğu halde tanısının yanlış konulduğu, \%20'sinin kanal basısının ise BT öncesi tespit edilemediği belirlenmiştir. ${ }^{[14,15]}$ Günümüzde BT, yüksek enerjili travmalarda sıklıkla yapılan ve değerlendirilen görüntüleme yöntemi olarak kabul görmüştür. Radyografi ile karşılaştırıldığında BT, kemik yapıları, spinal kanalı daha yüksek çözünürlükle gösterebilmektedir. BT genel olarak;
1) bilinci yerinde olmayan ve servikal yaralanması olduğu düşünülen hastalarda,

2) bilinci yerinde normal radyografileri mevcut ancak klinik olarak pozitif bulguları olanlarda,

3) yeterli radyografik değerlendirilmesi yapılamamış hastalarda,

4) radyografik şüpheli bulguları olan hastalarda ve

5) kırık paterni mevcut ancak karar verilemeyen hastalarda kullanılmaktadır. ${ }^{[16,17]}$

BT, kırık paternini belirleme ve ardışık omur yaralanmalarını göstermede radyografik değerlendirmeye göre daha iyi bir değerlendirme sağlar. BT, özellikle üst torakal seviyelerde omuz ve skapula pozisyonundan bağımsız olarak ve yine servikokraniyel bileşkede kemik ve yumuşak dokulardan etkilenmeksizin değerlendirmeye imkan tanır. Hızlı ve birden fazla planda elde edilen kemik yapı görüntüleri ile yaralanma mekanizmasının 

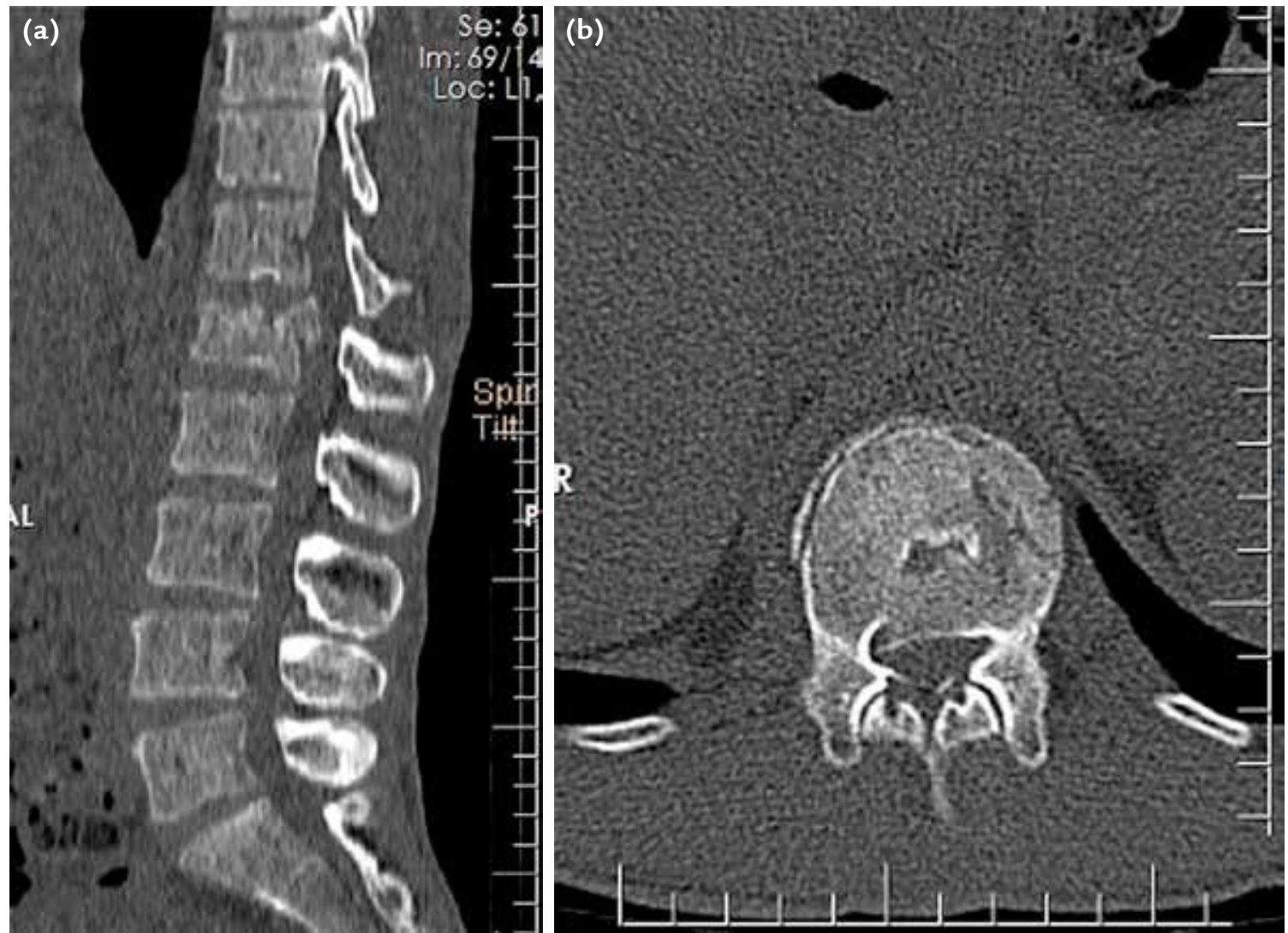

Şekil 2. a, b. Yüksekten düşme sonrası BT tetkikleri ile değerlendirme. L1 burst kırığı (a) ve aksiyel kesitte (b) kanal içi kemik parça görülmektedir.

daha erken dönemde tespit edilmesini sağlar. Özellikle deplasmanı olmayan aksiyel plan kırıkları BT ile tespit edilebilmektedir. Lomber bölge burst kırıklarında laminaya uzanan ve basıya neden olabilecek vertikal kırıkların tespitine olanak tanır. Omurga değerlendirmedeki üstünlüklerine rağmen akılda tutulması gereken, BT'nin kullanıcı bağımlı bir tetkik olduğudur. Alınan kesitler, iki ve üç boyutlu yeniden yapılandırmalar, cihaz kullanıcısına bağımlı parametrelerdir. Yine, çekim sırasında hastanın hareketli olması da görüntü kalitesini düşürebilir ve üst üste gelen görüntülemeler ile yanıltıcı olabilir. Yakın gelecekte kullanıc bağımlı̆̆ı ve harekete bağı bozulmalar muhtemelen yeni teknoloji ile aşılacaktır (Şekil 2).

\section{MANYETIK REZONANS GÖRÜNTÜLEME}

Düz radyografi, özellikle omurga yumuşak doku değerlendirmesinde ciddi şekilde sınırlı bilgi sağlarken, hızlı gelişen MR teknolojisi omurga travmasında yumuşak dokuyu ayrıntılandırarak omurga stabilitesi hakkında hekimlere değerli bilgiler sağlamaktadır. BT tetkiki miyelografi ile birlikte kullanıldığında, hematom, disk, kord ödemi ve darlık hakkında bilgi verebilirken, travmadaki sınırlı kullanımı, değerlendirme yapmak için MR'nin daha yaygın olarak kullanımını getirmiştir. Özellikle travma sonrası posterior ligamentöz kompleks, spinal kord, intervertebral disk aralığı gibi yumuşak dokuların ayrıntılı değerlendirilmesinde MR önemli avantajlar sağlamıştır. Çalışmalarda, omurga kırığı için BT'nin sensitivitesi \%80-100 (\%82) iken, MR'ninki \%25-70 aralığında gerçekleşmektedir. ${ }^{[18]}$ Ancak, omurga travmasında MR kullanmanın bir takım dezavantajları bulunmaktadır. Bunlar; teknolojik pahalılık, MR'ye ulaşımın her yerde mümkün olmaması, lojistik yetersizlikler ve görüntülerin diğer radyolojik değerlendirmelere göre daha uzun sürede elde edilmesi şeklinde sıralanabilir. Ayrıca, ciddi omurga veya çoklu organ yaralanmasına maruz kalan hastaya MR çekimi sırasında cihaz içerisinde ulaşabilmek, monitorize etmek ve gerektiğinde ventilasyon ve diğer destekleyici materyallerin 

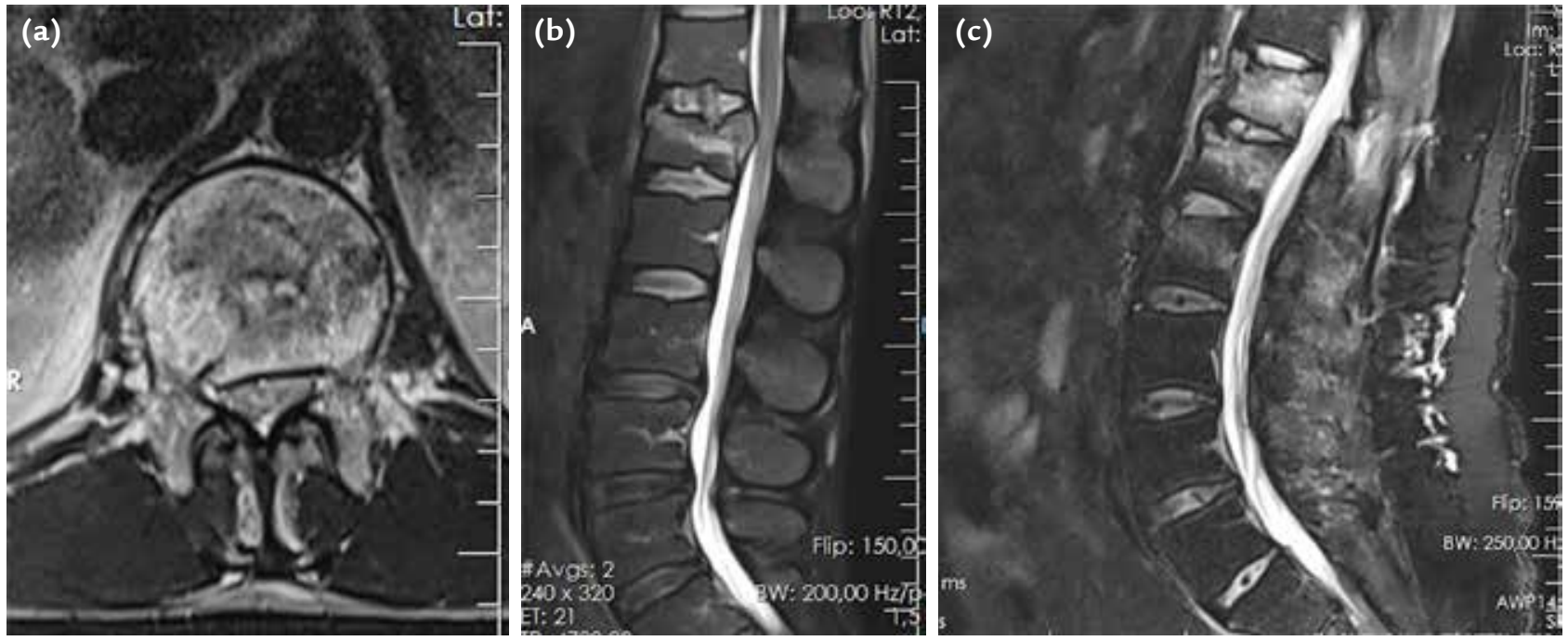

Şekil 3. a-c. Omurga travması sonrası MR görüntüleme. Hastanın aksiyel ve sagittal T2 baskılamalı MR görüntülerinde kanal içi kemik parçanın da olduğu, posterior ligamentöz bağların sağlam olduğu, stabil bir burst kırığı görülmektedir (a, b). Ardışık T12, L1 ve L2 seviyelerinde yükseklik kaybı ve ödem ile birlikte posterior ligamentöz bağların da yaralandığı stabil olmayan bir yaralanma görülmektedir (c).

kullanımı sınırlı olmaktadır. Kardiyak pacemakers ve anevrizmal klips varlığında kullanılamamaktadır.

Bir takım sınırlamalara ve dezavantajlara rağmen MR'nin mutlaka kullanılması gereken, örneğin nörolojik defisit varlığı gibi klinik durumlar mevcuttur. Akut travmada MR bulguları spinal kord yaralanması histopatolojik bulguları ile paralellikler göstermektedir ki bu da MR görüntülemenin spinal kord yaralanmasına maruz kalmış kişilerde uzun dönem prognostik bir tetkik olarak kullanılabilirliğini desteklemektedir. Travma sonrası spinal kord parankimal değişikliklerin MR bulguları baz alınarak nörolojik iyileşme sınıflandırması oluşturulmuş̧tur.

Tip 1: Ciddi parankimal yaralanma ile birlikte fizyolojik ve anatomik kesilmenin olduğu spinal kord değişiklikleri, bu tip yaralanmada kişide tam spinal kord defisiti mevcuttur ve motor iyileşme için kötü prognoza sahiptir.

Tip 2: İntramedüller ödem vardır. Tam olmayan nörolojik defisit ve fonksiyonel iyileşme için daha iyi prognoza sahip hasta grubudur.

Tip 3: Miks hemorajik ve ödem değişiklikleri mevcuttur. Nörolojik iyileşme açısından prognozu iyi olan gruptur. ${ }^{[19,20]}$

Daha önce geçirilmiş omurga travma öyküsü olan hastalarda MR görüntüleme, yaralanmanın akut mu yoksa geçirilmiş̧ bir travmaya mı bağlı olduğu; ayrıca, servikal bölgede vasküler yaralanma hakkında da bilgi verebilir. Travma sonrası gelişen syrinx kavitesi, geç nörolojik kötüleşmenin nedeni olabilecekken MR tetkiki ile belirlenebilir ve tedavisi planlanabilir.

Bunlarla birlikte, torakolomber burst ve Chance kırıları ile fleksiyon-distraksiyon yaralanmalarında posterior kolon ve ligamentöz kompleks değerlendirilmesi için MR değerlendirilmesi gerekecektir. X-ray ve BT kırığın anatomisi ve kanal işgali hakkında bilgi verebilecek, ancak bağ yaralanması ve stabilite hakkında yetersiz kalabilecektir. Özellikle son yıllarda yaygın olarak kullanılan TLICS (Thoracolumbar Injury Classification Severity Score) skorlamasında posterior ligamentöz kompleks bütünlüğü omurga travması sonrası hastaların tedavi planlamasında yaralanma mekanizması ve nörolojik durum ile birlikte değerlendirme içerisinde bulunmaktadır. Sağlam olarak tespit edilen posterior ligamentöz kompleks için 0; şüpheli veya orta seviyeli yaralanma için 1; ve yaralanma tespit edilmiş hastalarda ise 2 puan verilir (Şekil 3).

Sonuç olarak; torakolomber bölge yaralanmala$\mathrm{r}$, travma anında veya sonrasında hastanın yaşamını tehdit eden veya kalıcı sekellere neden olabilecek ciddi yaralanmalardır. Bu nedenle, hayatta kalabilmiş hastaların kalıcı sorunlarını en aza indirebilmek ve uygun önlemlerin zamanında alınabilmesi için, kapsamlı ve doğru bir fizik ve radyolojik değerlendirme, kritik ve çok önemli bir rol oynar. 


\section{KAYNAKLAR}

1. Colterjohn NR, Bednar DA. Identifiable risk factors for secondary neurologic deterioration in the cervical spineinjured patient. Spine 1995;20(21):2293-7. Crossref

2. Vaccaro AR, An HA, Lin S, Sun S, Balderston RA, Cotler JM. Noncontiguous injuries of the spine. J Spinal Disord 1992;5(3):320-9. Crossref

3. An HS, Vaccaro A, Cotler JM, Lin S. Spinal disorders at the cervicothoracic junction. Spine 1994;19 Suppl:2557-64. Crossref

4. Bohlman $\mathrm{HH}$. Acute fractures and dislocations of the cervical spine: an analysis of three hundred hospitalized patients and review of the literature. J Bone Joint Surg Am 1979;61(8):1119-42. Crossref

5. Atlas SW, Regenbogen V, Rogers LF, Kim KS. The radiographic characterization of burst fractures of the spine. Am J Roentgenol 1986;147(3):575-82. Crossref

6. Daffner RH, Deeb ZL, Rothfus WE. Fingerprints of vertebral trauma -a unifying concept based on mechanisms. Skeletal Radiol 1986;15(7):518-25. Crossref

7. Angtuaco EJC, Binet EF. Radiology of thoracic and lumbar fractures. Clin Orthop Relat Res 1984;(189):43-57. Crossref

8. Mehta JS, Reed MR, McVie JL, Sanderson PL. Weight-bearing radiographs in thoracolumbar fractures: Do they influence management? Spine 2004;29(5):564-7. Crossref

9. Jacobs RR, Asher MA, Snider RK. Thoracolumbar spinal injuries. A comparative study of recumbent and operative treatment in 100 patients. Spine 1980;5(5):463-77. Crossref

10. Panjabi MM, Hausfeld JN, White AA 3rd. A biomechanical study of the ligamentous stability of the thoracic spine in man. Acta Orthop Scand 1981;52(3):315-26. Crossref

11. Borock EC, Gabram SGA, Jacobs LM, Murphy MA. A prospective analysis of a two-year experience using computed tomography as an adjunct for cervical spine clearance. J Trauma 1991;31(7):1001-6. Crossref
12. Nunez DB, Ahrnad AA, Coin CG, LeBlang S, Becerra JL, Henry R, Lentz K, Quencer RM. Clearing the cervical spine in multiple trauma victims: a time-effective protocol using helical computed tomography. Emerg Radiol 1994;1(6):2738. Crossref

13. Ringenberg BJ, Fisher AK, Urdaneta LF, Midthun MA. Rational ordering of cervical spine radiographs following trauma. Ann Emerg Med 1988;17(8):792-6. Crossref

14. Ballock RT, Mackersie R, Abitbol J, Cervilla V, Garfin DR. Can burst fractures be predicted from plain radiographs? J Bone Joint Surg Br 1992;74-B(1):147-50. Crossref

15. Keene JS, Fischer SP, Vanderby R Jr, Drummond DS, Turski PA. Significance of acute posttraumatic bony encroachment of the neural canal. Spine 1989;14(8):799-802. Crossref

16. Katz MA, Beredjiklian PK, Vresilovic EJ, Tahernia AD, Gabriel JP, Chan PS, Heppenstall RB. Computed tomographic scanning of cervical spine fractures: does it influence treatment? J Orthop Trauma 1999;13(5):338-43. Crossref

17. Kathol MH. Cervical Spine Trauma: what is new? Radiol Clin North Am 1997;35(3):507-32.

18. Klein GR, Vaccaro AR, Albert TJ, Schweitzer M, Deely D, Karasick D, Cotler JM. Efficacy of magnetic resonance imaging in the evaluation of posterior cervical spine fractures. Spine 1999;24(8):771-4. Crossref

19. Bondurant FJ, Cotler HB, Kulkarni MV, McArdle CB, Harris JH Jr. Acute spinal cord injury: a study using physical examination and magnetic resonance imaging. Spine 1990;15(3):161-8. Crossref

20. O'Beirne J, Cassidy N, Raza K, Walsh M, Stack J, Murray P. Role of magnetic resonance imaging in the assessment of spinal injuries. Injury 1993;24(3):149-54. Crossref 